\title{
Book Review_Diagnostic pathology: neuropathology, 2nd edition
}

\author{
Aurelio Ariza ${ }^{1}$
}

Received: 4 July 2016 / Accepted: 6 July 2016 / Published online: 28 July 2016

(C) Springer-Verlag Berlin Heidelberg 2016

The second edition of Elsevier's "Diagnostic Pathology: Neuropathology," edited by B K Kleinschmidt-DeMasters, Fausto J Rodríguez, and Tarik Tihan, is hot off the press. Holding the volume in your hands and leafing through its 800 pages readily elicits a pleasant feeling that is well known to book lovers. This sensation soars as the 1700 superb quality images parade before your eyes. The telling illustrations, in conjunction with the potent distillation of knowledge provided by the text's pragmatic key points, efficiently shed a bright light on the ever-expanding field of surgical neuropathology.

In addition to central nervous system neoplasms and benign cysts, there are sections on infectious, inflammatory and reactive lesions, vascular diseases, and cortical dysplasia. In consonance with the Copernican advances experienced by neuropathology since the previous edition, many parts of the book have been thoroughly updated. In fact, all chapters have had their text and illustrations revised for this second edition, which masterly adopts the "integrated diagnosis" approach now in vogue.
Seasoned and young pathologists, as well as trainees, will find this book uniquely useful when dealing with surgical neuropathology issues. This work can be used as both a succinct, user-friendly consultation tool for deft confrontation of diagnostic problems and as a diaphanous learning source in which to acquire a sound knowledge of the essentials of surgical neuropathology in an enticing and gratifying way. Recourse to the eBook version, available at no additional charge, greatly enhances the teaching capabilities of this work, which bears witness to the didactic prowess of its authors on every page.

Bette K Kleinschmidt-DeMasters, Tarik Tihan \& Fausto Rodriguez (Eds.)

Print ISBN 9780323445924

$864 \mathrm{pp}$

$£ 192.99$

http://www.elsevierhealth.co.uk/diagnostic-pathologyneuropathology-9780323445924.html

Aurelio Ariza

aurelio.ariza@uab.cat

1 Department of Pathology, Hospital Germans Trias i Pujol,

Autonomous University of Barcelona, Barcelona, Spain 